\title{
A formação da metrópole paulista: um diálogo entre Richard Morse e Antonio Candido
}

\author{
[ The construction of São Paulo metropolis: a dialogue \\ between Richard Morse and Antonio Candido
}

\section{Ana Claudia Veiga de Castro ${ }^{\mathrm{x}}$}

RESUMO-O livro que Richard Morse publicou em 1954 - De comunidade a metrópole: biografia de São Paulo - pode hoje ser considerado um clássico na história da cidade. Partindo da comunidade fundada em I554 na América Portuguesa, a obra traça os caminhos que levaram a cidade a se tornar a principal metrópole brasileira. Para tanto, Morse indicava uma relação entre os diversos momentos históricos e o ethos paulista. Isso se evidencia quando se nota que o momento crucial do crescimento urbano paulista - o século XIX - se estrutura entre dois movimentos culturais da história da cidade: o Romantismo e o Modernismo. Tal perspectiva encontra na cidade um interlocutor privilegiado, que ajudaria a dar forma e conteúdo a sua obra. Em uma leitura rente ao livro de Morse, o texto pretende explorar o diálogo entre o historiador e Antonio Candido, buscando, na obra deste último, hipóteses para a compreensão do livro. • PALAVRASCHAVE - São Paulo; história da cidade; literatura; Richard Morse; Antonio Candido. •ABS-
TRACT - The book published by Richard Morse in 1954 - De comunidade a metrópole: biografia de São Paulo - nowadays can be considered a classic in the history of the city of São Paulo. From the community founded in I554 on a plateau in the countryside of a Portuguese settlement in America, the work traces the paths that have led the city to become the main Brazilian metropolis. By seeking this, Morse indicated a particular relationship between different historical moments and the Paulista ethos. Such perspective is realized when the urban growth of the city in the Igth century occurs between two literary movements of its history: Romanticism and Modernism. This perspective turns into the content of Morse's work. Thus, from a tuned reading of Morse's book, this paper seeks to explore the dialogue between Richard Morse and Antonio Candido, looking into the latter's work hypotheses to understand Morse's book. - KEYWORDS . São Paulo; history of city; literature; Richard Morse; Antonio Candido.

Recebido em 26 de agosto de 2015

Aprovado em I2 de julho de 2016

CASTRO, Ana Claudia Veiga de. A formação da metrópole paulista: um diálogo entre Richard Morse e Antonio Candido. Revista do Instituto de Estudos Brasileiros, Brasil, n. 66, p. 22I-238, abr. 2017.

DOI: http://dx.doi.org/Io.II6o6/issn.23I6-90IX.voi66p22I-238

I Universidade de São Paulo (USP, São Paulo, SP, Brasil). 
O livro que o historiador norte-americano Richard Morse publicou em I954, De comunidade a metrópole: biografia de São Paulo ${ }^{2}$ resultado da sua tese de doutorado defendida em I952 na Universidade de Colúmbia, em Nova York ${ }^{3}$-, pode hoje ser considerado um clássico da história da cidade ${ }^{4}$. Contemporâneo de obras como La croissance de la Ville de São Paulo, de Pierre Monbeig, publicado em I9535, ou História e tradições da cidade de São Paulo, de Ernani da Silva Bruno, de I954 ${ }^{6}$, o livro de Morse alcançou um lugar de destaque nos estudos sobre São Paulo, sobretudo após a sua republicação em I970 sob o título de Formação histórica de São Paulo: de comunidade a metrópole 7 , tornando-se uma referência aos interessados na história da cidade. Nem obra memorialística - como é o caso de Silva Bruno -, tampouco obra restrita aos muros da Academia - como se pode pensar do trabalho de Monbeig -, um dos interesses desse livro é o fato de poder ser lido como um ensaio sobre a formação da metrópole, trazendo em suas páginas uma visada compreensiva sobre a transformação urbana e social que ocorreu ao longo dos quatro séculos de existência

2 MORSE, Richard. De comunidade a metrópole: biografia de São Paulo. São Paulo: Fundação do IV Centenário, I954.

3 Idem. São Paulo. City under the empire (I822-I889). Tese (Doutorado). New York: Columbia University, I952.

4 Para Antonio Candido, esse "livro forte e pessoal, [seria] talvez a melhor monografia até hoje escrita sobre a cidade”. CANDIDO, Antonio. Young Mr. Morse. In: BOMENY, Helena (Org.). Um americano intranquilo. Rio de Janeiro: Ed. FGV, I992, p. 7-I2. p. 7 (grifos nossos). Segundo Carlos Guilherme Mota, "seu primeiro livro tornou-se um clássico sobre São Paulo". MOTA, Carlos Guilherme. Um americano intranquilo. In: BOMENY, Helena (Org.). Um americano intranquilo. Rio de Janeiro: Ed. FGV, I992, p. I4. Também já se disse que "o livro, que começa a circular em I970, é referência obrigatória para os estudiosos das cidades em geral, e uma das grandes monografias a que os paulistanos fizeram jus". CARVALHO, Maria Alice Rezende de. Morse e o mar. In: Quatro vezes cidade. Rio de Janeiro: 7 Letras, I994, p. I05 (grifos nossos). Exploramos a fortuna crítica do livro em outra oportunidade: cf. CASTRO, Ana. Leituras e leitores de Richard Morse: a trajetória de um livro sobre a formação da metrópole paulista. Anais do Museu Paulista, São Paulo, v. 2I, p. I79-I93, 2013.

5 MONBEIG, Pierre. La croissance de la Ville de São Paulo. Grenoble: Institut et Revue de Géographie Alpine, I953.

6 BRUNO, Ernani da Silva. História e tradições da cidade de São Paulo. São Paulo: Jose Olympio, I954. 3 v.

7 MORSE, Richard. Formação histórica de São Paulo: de comunidade a metrópole. São Paulo: Difel, I970. 
de São Paulo, sem entretanto deixar de ter o rigor de uma obra científica, oferecendo desse modo material e referências para pesquisadores de diversas áreas interessados na cidade.

Assim como Silva Bruno ou Monbeig, Morse também partiu da comunidade fundada em 1554 num planalto do interior da América Portuguesa para traçar os caminhos que teriam levado São Paulo a se tornar no meio do século XX a principal metrópole brasileira. No entanto, diferentemente daquelas e de outras obras sobre a história da cidade, além de inserir a cidade num campo de interesses e forças mais amplo, a América Latina, Morse indicava uma relação particular entre os momentos históricos e o ethos paulista, tomando-a como chave de compreensão da metrópole. Dessa forma, distanciava-se das explicações sociológicas stricto sensu, vendo, menos que uma correspondência imediata entre ciclos econômicos (sobretudo aquele ligado ao café) e urbanização da cidade, uma espécie de transformação "mental" que teria garantido à cidade e aos seus habitantes a capacidade de lidar com as mudanças sociais e econômicas, para se tornar uma metrópole.

Tal perspectiva de análise se evidencia quando se nota que o livro estrutura o momento crucial do crescimento urbano paulista - o século XIX - entre dois movimentos literários, ou culturais, da história de São Paulo: o Romantismo e o Modernismo. Diferententemente das explicações que elegiam o trinômio café-imigração-ferrovia como a chave de entendimento para a urbanização intensa da virada do século, Morse tentou compreender como a cidade vivenciou esse desenvolvimento e como seus habitantes lidaram com isso, deslocando o foco para o início do século XIX, a partir da Independência, quando um novo ethos começa a ser gestado, tomando a literatura como sua principal porta de acesso à compreensão desse ethos. Essa perspectiva analítica, se foi sendo elaborada ao longo da sua formação em Nova York ${ }^{8}$, encontraria um interlocutor privilegiado na capital paulista, que, me parece, ajudou a dar forma e conteúdo às inquietações do jovem pesquisador.

Este texto pretende explorar o diálogo entre Richard Morse e Antonio Candido, buscando na obra deste último algumas hipóteses para a compreensão do modo como Morse elaborou seu livro\%. Busca-se aqui estabelecer relações entre os argumentos que amparam a compreensão da história da cidade traçada por Morse e as perspectivas esboçadas por Antonio Candido da literatura feita em São Paulo, a partir sobretudo do ensaio "A literatura na evolução de uma comunidade", também publicado em I954 ${ }^{\mathrm{TO}}$. Nesse artigo, recuperando autores desde a Colônia, o crítico brasileiro buscava

8 Em sua formação como historiador em Princeton e posteriormente em seu doutorado em Colúmbia, Morse sempre esteve ligado aos professores menos "especialistas" ou àqueles que defendiam a literatura como uma chave para a compreensão do passado. Cf. CASTRO, Ana. Um americano na metrópole (latino-americana): Richard Morse e a história cultural urbana de São Paulo, I947-I970. Tese (Doutorado - Área de Concentração: História e Fundamentos da Arquitetura e Urbanismo). Faculdade de Arquitetura e Urbanismo - FAU, Universidade de São Paulo - USP, 20I3.

9 Tomo a edição de I954 como base da análise, porque as mudanças entre essa e a edição de I970 se concentram na "Introdução" e no capítulo final e não incidem diretamente no que se analisa aqui.

Io CANDIDO, Antonio. A literatura na evolução de uma comunidade. (I954). In: Literatura e sociedade: estudos de teoria e história literária. São Paulo: T. A. Queiroz, 2000, p. I39-I68. 
"delimitar produções e autores segundo o critério mais compreensivo e certo da participação na vida social e espiritual da cidade”. Isso porque, de seu ponto de vista, a cidade apresentava "algumas características, e [era] compreensível que a sua influência mar[casse] literariamente os que nela viv[ia]m, de modo mais forte que as do lugar onde nasceram" "I. Se uma obra é única, a literatura é coletiva, ensina Candido, e por isso ela pode ser índice de compreensão da vida social. Nesse caso, tratava-se de caracterizar as "diferentes etapas da literatura brasileira em São Paulo”, reconhecendo a ligação orgânica entre produção literária e vida social, pois a literatura requeria "uma comunhão de meios expressivos (a palavra, a imagem) e mobilizava afinidades profundas que congregam os homens de um lugar e de um momento" para chegar no seu objetivo, que é a comunicação ${ }^{\text {I2 }}$.

Assim, não há literatura enquanto não houver essa congregação espiritual e formal, manifestando-se por meio de homens pertencentes a um grupo (embora ideal), segundo um estilo (embora nem sempre tenham consciência dele); enquanto não houver um sistema de valores que enforme a sua produção e dê sentido à sua atividade; enquanto não houver outros homens (um público) aptos a criar ressonância a uma e outra; enquanto, finalmente, não se estabelecer a continuidade (uma transmissão e uma herança), que signifique a integridade do espírito criador na dimensão do tempo ${ }^{\mathrm{I} 3}$.

Morse, por motivos que vamos ver adiante, viu no surgimento da Academia de Direito o estabelecimento da possibilidade de São Paulo ser entendida como cidade. Candido viu a mesma Academia como a possibilidade de a cidade abrigar uma "literatura" - quando passa a existir o que o crítico chamou posteriormente de sistema literário - livro, autor e público, ou, dito mais precisamente, obra, escritor e tradição literária. Assim, a ideia de sistema, que caracterizará a apreciação de Antonio Candido sobre a formação da literatura brasileira, aparece aqui em elaboração, para pensar a literatura paulista. Segundo esse critério, só haveria literatura em São Paulo a partir da Independência, e notadamente depois do advento da Faculdade de Direito do Largo São Francisco - ainda que antes, na segunda metade do século XVIII, já se esboçassem as condições para que uma literatura paulista pudesse surgir, havendo, portanto, "manifestações literárias", como Candido formaliza na sua obra-mestra de I959 ${ }^{\mathrm{I}}$. E, para pensar como Morse com as palavras de Candido, só quando o sistema se rotiniza é que São Paulo se torna de fato "cidade”. Mas não apressemos o passo e vejamos de início como se deu o "encontro" entre Richard Morse e Antonio Candido.

Quando chegou a São Paulo em I947, com uma ideia mais ou menos formada

II Ibidem, p. I42.

I2 Ibidem, p. I39.

I3 Ibidem, p. I40.

I4 Desde I945 Antonio Candido escrevia uma história da literatura brasileira a convite do editor Martins, que finalmente se transformou, como se sabe, num estudo sobre a literatura brasileira no qual o Arcadismo e o Romantismo seriam entendidos como momentos-chave de formação do que ele chamou de "sistema literário brasileiro”. CANDIDO, Antonio. Formação da literatura brasileira: momentos decisivos. São Paulo: Martins, I959. $2 \mathrm{v}$. 
sobre o que o motivava a estudar essa cidade - compreender a urbanização intensa de uma capital latino-americana em pleno desenvolvimento industrial ${ }^{15}$ -, Richard Morse deparou-se não apenas com uma cidade espacialmente em ebulição, que renovava sua paisagem urbana de maneira intensa ${ }^{16}$, mas também com uma universidade jovem, que contava com a primeira geração de alunos agora transformada em professores começando a ditar os rumos do pensamento intelectual na capital. Eles ocupavam postos de docentes na Universidade de São Paulo, espaços nos jornais e nas revistas como críticos profissionais, e logo cargos de direção em instituições culturais que passavam a ser criadas. Dispostos a pensar o Brasil em termos científicos, esses jovens intelectuais buscaram produzir novas teorias de interpretação, contribuindo para o campo do pensamento social e da crítica da cultura, a partir de entradas diversas ${ }^{17}$. Entre eles, Antonio Candido, docente da cadeira de Sociologia 2 da Faculdade de Filosofia, firmava-se também como crítico literário $^{18}$. Seu trabalho crítico seria fundamental para historicizar o Modernismo, incluindo-o na tradição literária. Mas, além disso, ao dar ao movimento certo protagonismo no estabelecimento de uma literatura autônoma, Candido consequentemente inseria São Paulo, palco principal do movimento, numa perspectiva nacional. Compartilhava assim do ponto de vista esboçado pelo próprio Mário de Andrade - ele mesmo protagonista e intérprete primeiro do movimento -, que poucos anos antes, ao formular um juízo crítico sobre o Modernismo, notara alguma equivalência entre esse movimento e o Romantismo:

I5 "Aquela coisa de São Paulo havia ficado na minha mente: por que surgira aquela cidade enorme que todo o mundo dizia ser a Chicago da América do Sul, e que forças econômicas teriam eliminado de sua paisagem quase todos os sinais de uma tradição arquitetônica anterior?”. BOMENY, Helena. Uma entrevista com Richard Morse. Estudos Históricos, FGV, Rio de Janeiro, v. 2, n. 3, , I989, p. 77-93. p. 77.

I6 Morse permanece em São Paulo de setembro de I947 a dezembro de I948, com uma bolsa do Departamento de Estado norte-americano. Esse é o período em que o processo de metropolização da cidade ganha força: verticalização intensa das áreas centrais, espraiamento da mancha urbana e reforço da ideia de centro como o coração da metrópole.

I7 Entre os que começavam a protagonizar essa cena, Florestan Fernandes, Antonio Candido, Decio de Almeida Prado, Paulo Emilio Salles Gomes e Gilda de Mello e Souza. Sobre a atuação desses intelectuais dentro e fora da universidade e seu papel na construção da crítica de arte no Brasil, entre outros, ver: PONTES, Heloisa, Destinos mistos: os críticos do Grupo Clima em São Paulo (I940-68). São Paulo: Companhia das Letras, I998.

I8 Candido, professor assistente em Sociologia, defende sua tese em I954, ao mesmo tempo que já era um crítico literário respeitado. Presta concurso para a Faculdade de Letras da USP e não é aprovado, mas em I958 opta definitivamente pelas Letras, mudando-se para Assis, onde assume a cadeira de Teoria Literária da Unesp. Vale notar que a Formação estava sendo escrita portanto concomitantemente com sua tese em Sociologia. Sobre as indefinições que o intelectual parece viver justamente no período em que Morse está em São Paulo até a publicação do livro, ver: RAMASSOTE, Rodrigo Martins. Antonio Candido em Assis e depois. Revista do Instituto de Estudos Brasileiros, USP, São Paulo, n. 50, mar. 20Io, p. I03-28; CARDOSO, Fernando Henrique. A fome e a crença (sobre Os parceiros do Rio Bonito). In: Esboço de figura: homenagem a Antonio Candido. São Paulo: Duas Cidades, I979, p. 89-Ioo; e JACKSON, Luiz Carlos. A tradição esquecida. Os Parceiros do Rio Bonito e a sociologia de Antonio Candido. Belo Horizonte: Ed. UFMG; São Paulo: Fapesp, 2002. 
Nós tivemos no Brasil um movimento espiritual (não falo apenas escola de arte) que foi absolutamente "necessário", o Romantismo. [...] Este espírito preparou o estado revolucionário de que resultou a independência política, e teve como padrão bem briguento a primeira tentativa de língua brasileira. O espírito revolucionário modernista, tão necessário como o romântico, preparou o estado revolucionário de 30 em diante [...]. A similaridade é muito forte ${ }^{\mathrm{I}}$.

Ambos os movimentos, como se disse, são tomados na obra de Morse como momentos de redefinição de sensibilidades e de florescimento de mudanças na cidade de São Paulo. Afirmando que o artista "não retrata diretamente a sociedade de sua época na sua obra [...] [mas] a absorve, funde e transmuta de maneiras sutis e pessoais [...], abertas à análise do pesquisador" ${ }^{20}$, Morse - nesse livro, aliás, dedicado a Mário - defendia que a literatura podia e devia se transformar em matéria da história da cidade, abrindo portas para a compreensão do passado, pois, como afirmara certa feita o poeta, "os movimentos espirituais precedem sempre as mudanças de ordem social” "2x. Por isso, eram Álvares de Azevedo e o próprio Mário de Andrade mobilizados por Morse como "leitores privilegiados" da cidade, portadores de "habilitações culturais, profissionais e estéticas que os dota[ria]m de um olhar refinado, sensível e arguto" 22 , na formulação precisa de uma historiadora, podendo fornecer ao leitor contemporâneo as chaves de compreensão daquela jovem metrópole. Vejamos como.

\section{ROMANTISMO E PRENÚNCIO DE AUTONOMIA: UM NOVO ETHOS}

A partir da Independência, com o estabelecimento da imprensa, a criação da Academia de Direito e a formação de uma nova burocracia local unida ao poder nacional - três fatores catalisadores das mudanças posteriores -, Morse identifica em São Paulo o surgimento de um novo ethos, distante do mundo colonial e particularmente ligado ao mundo letrado, que levava a situação urbana a começar a se transformar. Imprensa, academia, administração pública distinguiam a cidade - que passava a abrigar o movimento romântico - da antiga comunidade colonial dos três séculos

I9 ANDRADE, Mário de. O Movimento Modernista. In: . Aspectos da literatura brasileira. São Paulo:

Martins, I942, p. 242.

20 MORSE, Richard. O pesquisador social e o historiador moderno. Revista do Arquivo Municipal, São Paulo, n. II3, p. 36-52, I949, p. 33.

2I ANDRADE, Mário de, op. cit., I942, p. 242.

22 PESAVENTO, Sandra. Muito além do espaço: por uma história cultural do urbano. Estudos históricos, FGV, Rio de Janeiro, n. I6, I995, p. 279-90. p. 284. 
precedentes ${ }^{23}$. O juízo coincide com a apreciação de Antonio Candido sobre o que teriam sido "os primeiros feitos de nossas classes por assim dizer esclarecidas" ${ }^{24:}$

Foi todavia com a vinda de D. João VI que o Brasil conheceu realmente, embora em escala modesta, a sua época das Luzes, como entrosamento da iniciativa governamental, do pragmatismo intelectual, da literatura aplicada, que finalmente convergiram na promoção e consolidação da Independência. [...] Imprensa, periódicos, escolas superiores, debate intelectual, grandes obras públicas, contato livre com o mundo [...] assinalam o reinado americano de D. João VI, obrigado a criar na Colônia pontos de apoio para o funcionamento das instituições 25 .

Momento "iluminista" da cultura nacional, que teria possibilitado o surgimento do movimento romântico, o qual, na compreensão do crítico, menos que pela ruptura com os árcades (ainda que completamente distinto do ponto de vista estético), caracterizava-se pelos pontos de continuidade na construção de algo que iria começar a ser chamado de "literatura brasileira", parte de um esforço maior de construção do país ${ }^{26}$. Aquela produção literária, que manifestava um "desejo de autonomia, tornado mais vivo depois da Independência”, era vista então como um dos momentos formativos da nossa literatura: "O Romantismo apareceu aos poucos como caminho favorável à expressão própria da nação recém-fundada, pois fornecia concepções e modelos que permitiam afirmar o particularismo, e portanto a identidade, em oposição à Metrópole, identificada com a tradição clássica”²7.

Tratava-se da construção de uma identidade local em oposição à metrópole e, no que importa mais de perto aqui, tendo São Paulo como locus privilegiado de desenvolvimento, já que a elite intelectual formada pelos estudantes de direito cuja sociabilidade mundana fazia surgir na cidade novos espaços e mentalidades - era quem buscava se expressar em termos independentes em relação à literatura

23 MORSE, Richard, op. cit., I954, p. 44 e ss.

24 ARANTES, Paulo. Providências de um crítico literário na periferia do capitalismo. In: ARANTES, Paulo; ARANTES, Otilia Beatriz Fiori. Sentido da formação: três estudos sobre Antonio Candido, Gilda de Mello e Souza e Lucio Costa. São Paulo: Paz e Terra, I997, p. II-66. p. 56.

25 Antonio Candido apud ARANTES, Paulo, op. cit., I997, p. 56.

26 Como sabemos, o Romantismo, momento em que começa a surgir o sentido "moderno" da palavra literatura, é o movimento literário geralmente relacionado com a afirmação de identidades nacionais - basta pensarmos no romantismo alemão ou inglês. Mas Candido retrocede ao Arcadismo - comumente visto como um movimento de cunho mais universalista - para flagrar ali os primeiros impulsos nacionais.

27 CANDIDO, Antonio. O Romantismo no Brasil. São Paulo: Humanitas, 2004. Mobilizo aqui, para efeitos práticos, esse texto escrito em I990 para um público estrangeiro, em que o crítico apresenta de modo resumido as características principais do movimento romântico no Brasil. Tais formulações, que foram sendo construídas ao longo da sua trajetória intelectual, não diferem essencialmente das esboçadas no meio do século XX. 
portuguesa ${ }^{28}$. A Academia daria origem a um grupo - os estudantes -, "dotado de forte espírito corporativo", constituindo "um público literário privilegiado e uma caixa de ressonância para a literatura, que se difundiria em parte por meio deles" e que, além de funcionar como "ambiente que estimulava a produção", também "fornec[er]ia um primeiro nível de receptividade crítica e afetiva" 29 . Esboçava-se assim o sistema, o que para Morse pareceu refletir a própria formação do que viria a ser a metrópole. Os jovens de elite que se mudaram para a pacata vila eram quem atuava para transformá-la, e por isso a Academia era um dos catalisadores da transformação. Para acompanhar essa transformação, a produção do artista seria potencialmente reveladora: "O artista é com frequência o símbolo mais satisfatório para captar refletir os processos vivos de uma sociedade. [...]. O artista é, a um tempo, mais capaz de compartilhar-se e envolver-se, e de ser mais objetivo do que seus semelhantes" ${ }^{\prime 30}$.

Para Morse, "quem mais de perto refletiu todo o espectro desses lampejos na cidade em transformação" foi Manuel Antonio Álvares de Azevedo. Como o poeta "pertencia [...] mental e emocionalmente à cidade", ele foi o símbolo daquele momento de transição vivido por São Paulo. Mas o autor de Macário e Noite na taverna não era "somente símbolo da adoção 'consciente' dos padrões específicos estrangeiros pela cidade, como [era] também de uma fusão multiforme e 'subconsciente' de elementos que racionalmente não se podem discernir" ${ }^{31}$, revelando o momento ambíguo que se vivia. "Tal como a cidade em que vivia, [Azevedo] foi compelido a fazer uma seleção entre as culturas estrangeiras e a refundir esses elementos”, por isso, seu discurso revelava a própria cidade, ela mesma buscando uma síntese entre a modernização e a permanência das suas tradições ${ }^{32}$. Ora, havia mudança, mas não rompimento: 0 passado continuava informando o presente, sustentando mentalmente o surgimento da metrópole. Se os anos românticos viam afrouxar "a tesa rede dos costumes e superstição", era porque na comunidade colonial todas as atividades se davam no

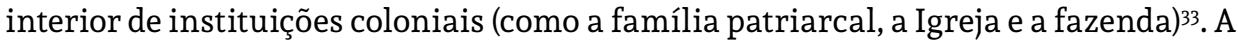
cidade que recebera a Academia, entretanto, pedia novos espaços e novas instâncias, explodindo aquele primeiro círculo de relações. Os exemplos de espaços públicos que surgiam - hotéis, restaurantes, boliches, tavernas - se somavam em seu livro

28 Na verdade, "a alegada independência" teria sido, em parte - seguindo aqui a interpretação de Candido - "uma substituição de influências, com a França tomando o lugar da metrópole portuguesa”. CANDIDO, Antonio. Iniciação à literatura brasileira. Rio de Janeiro: Ouro sobre Azul, 2004, p. 52. Vale aqui a mesma ressalva da nota anterior.

29 Ibidem.

30 MORSE, Richard, op. cit., I954, p. 87.

3I Ibidem.

32 Ibidem, p. 92 (grifos nossos).

33 Ibidem, p. 94. Morse descreve, por exemplo, uma série de incidentes protagonizados pela estudantada na cidade para mostrar como as crendices e superstições começavam a ser contestadas, numa clara mostra de avanço da razão objetiva sobre os costumes. Entretanto, num deles, conta como um estudante espalha um boato na cidade através de sua lavadeira - ação possível apenas numa pequena vila onde os contatos ainda se faziam familiares. Nota-se assim a ambivalência de tal momento. 
para mostrar que a cidade ia tomando "consciência" das novas possibilidades "para a vida individual e para a vida social”, e assim os paulistas, no meio do século XIX, começavam a "avaliar sua civilização e suas tradições regionais, enriquecê-las e diversificá-las pelo enxerto de novos modos e valores”, ainda que, insisto, sem perder a especificidade que os caracterizara, forjada nos anos coloniais ${ }^{34}$.

Após um primeiro impulso simbolizado pela sua fundação, a Academia veria arrefecer sua potência transformadora, traduzida na queda no número de matrículas, para "no espaço de uma geração", contudo, ressurgir com mais força e mostrar como "já estavam incorporadas no padrão brasileiro de valores as novas dimensões de indagação e abstração de que ela era o símbolo, e as novas carreiras urbanas, de natureza literária ou jurídica, que propiciava"35. Levando adiante o raciocínio, o autor mostrava que o "renascimento da Academia de Direito" lhe sugeria duas hipóteses complementares: "que ela se adaptava às necessidades dos tempos e que São Paulo [...] começava a exigir um novo tipo de cidadão mais instruído e dotado de uma visão inteiramente nova das coisas" ${ }^{36}$. É importante notar que o historiador refaz a trama que torna a cidade inteligível na mescla de documentos, depoimentos e literatura. Contudo, nessa urdidura, é Macário que lhe fornece "a visão ampla e espontânea da cidade” porque, escrita sem o objetivo de descrevê-la ou explicá-la, a obra provê imagens da própria transformação. O texto literário é mobilizado não como comprovação de uma tese elaborada a priori, mas como fio condutor de um raciocínio elaborado no embate com a própria cidade e com formulações e intrepretações que surgiam naqueles anos, como a levada à frente por Antonio Candido.

Àquela altura, Candido já se tornara um nome conhecido na cena intelectual, publicando críticas nos rodapés da Folha da manhã e do Diário de S. Paulo e concebendo em I956 o Suplemento Literário d'O Estado de S. Paulo37. Dois anos antes, dentro das comemorações do IV Centenário, Antonio Candido publicaria nesse mesmo jornal o artigo "A literatura na evolução da comunidade”. O crítico, que buscaria elaborar menos uma história da literatura que a história da formação da literatura - a partir da análise de seus "momentos decisivos", justamente o subtítulo da obra publicada em I959 -, nesse texto de I954 discutia "as formas de sociabilidade intelectual, e da sua relação com a sociedade, na caracterização das diferentes etapas da literatura brasileira em São Paulo"38. Para tanto, Antonio Candido dividiu a história da cidade em cinco fases correspondentes a cinco momentos literários ou cinco "grupos

34 Ibidem, p. 98-Ioo.

35 Ibidem, p. 97.

36 Ibidem, p. 99 (grifos nossos).

37 Sobre a atuação de Candido dentro e fora da universidade e seu papel na construção da crítica literária no Brasil, ver: SÜSSEKIND, Flora. Rodapés, tratados e ensaios: a formação da crítica brasileira moderna. In: Papéis colados. Rio de Janeiro: Ed. UFRJ, 2002, p. I5-36. Vinicius Dantas também ajuda a matizar a posição acadêmica de Antonio Candido, discutindo seu papel na institucionalização da crítica e na criação de um método. DANTAS, Vinicius. Apresentação. In: Antonio Candido. Textos de Intervenção. (Seleção, apresentação e notas de Vinicius Dantas). São Paulo: Duas Cidades e Ed. 34, 2009, p. I5-36.

38 CANDIDO, Antonio, op. cit., (I954), 2000, p. I43. 
letrados". O primeiro deles, "um grupo virtual" - Frei Gaspar da Madre de Deus, Pedro Taques de Almeida e Claudio Manoel da Costa, intelectuais que teriam forjado a personalidade "paulista" ao engendrar: "a consciência heroica do passado emergindo do sentimento nativista, [que] aparece como recurso de integração; como justificação de uma sociedade em crise de reajustamento de suas atividades" 39 .

Em seguida, o crítico identificava um "grupo real", ligado a um pré-romantismo que se estabelecera com a criação da Faculdade de Direito, a desempenhar papel decisivo na literatura em São Paulo. Para Morse, como vimos, papel decisivo na própria constituição da cidade. Na fase seguinte, quando o "grupo se justapõe à comunidade", observa-se a formação do burgo de estudantes. Se antes os estudantes tinham sido "meninos de família como os outros" e depois seriam "letrados, políticos e proprietários como os outros", no breve curso da Academia “foram algo diferente", numa São Paulo, como diz Candido, que ainda não os assimilara. Mas justamente desse caráter de exceção se nutria "sua sociabilidade particular [...] e uma expressão intelectual própria"40. O crítico parece atinar aí com o circuito apresentado em I9594'. Morse, por seu turno, valia-se de formulação semelhante para compreender quando e como São Paulo se tornara cidade, vislumbrando nesse momento a transformação de um substrato cultural paulista forjado na colônia paulatinamente se tornando híbrido, por mesclar-se aos valores capitalistas que começam a penetrar naquele espaço, o que em seguida sustentaria a própria modernização de São Paulo.

\section{MODERNISMO E METROPOLIZAÇÃO: UM ETHOS ENTRE O LOCALISMO E O COSMOPOLITISMO}

Ora, se nos anos românticos São Paulo se tornou “cidade”, como defende Morse, para o sociólogo-crítico literário foi no período subsequente - precisamente quando "a comunidade absorve o grupo", entre I890 e I9Io - que a cidade se tornou "outra". Antes, tinha 70 mil habitantes. Agora, contava com 240 mil. Transformada em centro ferroviário, comercial e político e onde uma indústria começava a aparecer, nela "não

39 Ibidem, p. I44. A "crise" em questão era o fim do período do ouro, a decadência das Minas, e a dispersão dos filhos paulistas, que os levaria a cantar o passado de glória. Frei Gaspar cria as bases do Romantismo ao valorizar o índio, para na sequência Pedro Taques aristocratizar as Bartiras em "princesas de sangue brasílico". Nota-se um "paulistanismo" ideologicamente configurado a nortear as obras dos três escritores, em que "as tonalidades características, que serviriam para definir a consciência do paulista moderno, [...] operariam como poderosa arma de sentimento de classe, de um lado, e de assimilação dos forasteiros, de outro". Ibidem, p. I45-I46.

40 Ibidem, p. I50.

4I Ibidem, p. I47-57. Talvez tenha sido na observação do momento em que a Academia se estabeleceu em São Paulo que ele notou a potência desse esquema com mais clareza: ao falar do satanismo em Álvares de Azevedo, Candido passa necessariamente pela ideia de uma comunidade da Faculdade de Direito que sustenta o surgimento do movimento romântico e, nesse sentido, ressalta a contribuição de São Paulo para a formação da literatura nacional, por constituir ali um sistema de livros, leitores e autores. 
ha[via] mais escravos, os caipiras [iam] sumindo, chega[v]am magotes de italianos, espanhóis, portugueses, alemães"². Do ponto de vista literário, menos que o valor estético, "o importante foi que a comunidade absorveu a literatura, que deixou de ser um grupo" ${ }^{3}$. Tratava-se da literatura parnasiana, manifestação literária que Morse utilizou de forma operativa, apenas como portadora de exemplos da transformação da cidade. A sua perspectiva parece ser uma vez mais coincidente com a de Candido, e por isso ele não pode eleger ali um "criador de símbolo" - como fez com Álvares de Azevedo anteriormente e fará com Mário de Andrade em seguida44. É como se um ethos moderno não estivesse ainda totalmente formado na cidade, fazendo com que houvesse naquela literatura apenas "um certo aristocratismo intelectual, certo refinamento de superfície, tão do agrado da burguesia, que nele encontra uma atmosfera confortável e lisonjeira", nas palavras de Candido 45 , e não outro momento estético forte que rendesse acesso potente à cidade ${ }^{46}$.

Mas, quando em seguida o Modernismo literário tornou-se expressão corrente da comunidade, foi porque o ethos moderno finalmente se constituiu - ou "o grupo se desprende[u] da comunidade"47. Entre I922 e I935, viveu-se em São Paulo uma "profunda renovação literária, estreitamente ligada à constituição de um agrupamento criador, como era o dos estudantes românticos; não mais justapostos à comunidade, todavia, mas formado a partir dela, oriundo de sua própria dinâmica, diferenciando-se de dentro para fora - por assim dizer"48.

Ao historicizar o movimento acontecido havia apenas três décadas, Antonio Candido assumia (ou propunha) aquela que se tornou a interpretação corrente, a de que em São Paulo pôde surgir um movimento renovador porque, não sendo cosmopolita como era a capital, tal renovação pudera reverberar - justamente pelo provincianismo reinante. Ao mesmo tempo, havendo ali uma elite mais ou menos esclarecida, também ela exerceu seu papel, apoiando os jovens artistas quando necessário, comprando suas obras e os colocando em contato com as vanguardas europeias, ao manterem salões que se tornaram o ambiente propício para os paulistas serem modernos. Candido ecoava assim a interpretação de Mário publicada poucos anos antes, cuja primeira frase revela a intenção de colocar o movimento no fluxo da história nacional: "Manifestado especialmente pela arte, mas manchando também

42 Ibidem, p. I57.

43 Ibidem, p. I58.

44 No artigo anteriormente citado, Morse diferenciava "um romancista de primeira" de "um de segunda", o que ajuda a entender o ponto. MORSE, Richard, op. cit., I949, p. 46.

45 CANDIDO, Antonio, op. cit., 2000, p. I58.

46 Morse citava em seu livro apenas uma cena do romance A carne, de Julio Ribeiro, em que a protagonista Lenita sonha em morar num palacete da Avenida Paulista apenas para mostrar a "ostentação vulgar e sem distinção" que aparecia tanto no desejo quanto no dia a dia da moça, refletindo "de modo não muito falso o materialismo superficial da cidade [note-se, não da protagonista, mas da cidade] e o seu impulso para a ostentação nos gastos". MORSE, Richard, op. cit., I954, p. 204-5.

47 CANDIDO, Antonio, op. cit., 2000, p. I60.

48 Ibidem (grifos nossos). 
com violência os costumes sociais e políticos, o movimento modernista foi o prenunciador, o preparador e por muitas partes o criador de um espírito nacional"49.

Moderna e provinciana ao mesmo tempo, foi nessa cidade que literatos caipiras de serra-acima puderam lançar as bases da vanguarda brasileira, acertando os ponteiros da arte nacional inclusive - ou sobretudo - por terem que se haver com o próprio Brasil como matéria artística. Ao destacar em seu ensaio que tanto Romantismo quanto Modernismo haviam sido "dois momentos em que a cidade se projet[ou] sobre o país, e procur[ou] dar estilo às aspirações do país todo”, na esteira de Mário, Antonio Candido também mostrava como "literatura e cidade, ambas se explicam e se complementam, se as quisermos ver solidariamente" 50 . Foi nessa "solidarização" que ele buscou compreender a história da cidade por meio de sua literatura, afirmando que

[...] o Modernismo não foi apenas um movimento literário, mas, como tinha sido o Romantismo, [foi] um movimento cultural e social de âmbito bastante largo, que promoveu a avaliação da cultura brasileira, inclusive porque coincidiu com outros fatos importantes no terreno político e artístico, dando a impressão de que na altura do Centenário da Independência (I922) o Brasil efetuava uma revisão de si mesmo e abria novas perspectivas, depois das transformações mundiais da guerra de I9I4-I9I8, que aceleraram o processo de industrialização e abriram um breve período de prosperidade para o nosso principal produto de exportação, o cafésI.

Por isso a década de I920 era especialmente propícia para flagrar o surgimento de uma literatura nacional e, mais que isso, de uma literatura que finalmente se colocava em pé de igualdade com as literaturas europeias. Candido cunharia a expressão "desrecalque localista" para os efeitos da literatura modernista na nossa sociedade: onde os românticos apelaram para o nacionalismo, os modernistas recorreram à piada, fazendo render o que antes nos envergonhava ${ }^{52}$. $\mathrm{O}$ trabalho de Morse, num certo sentido, também pode ser tomado como uma tentativa de "desrecalcar" a capital paulista frente às capitais e metrópoles centrais ao propor haver aqui uma cultura própria e tradicional, híbrida entre o ethos católico e o capitalista, e ao mesmo tempo moderna.

Mas que espécie de metrópole era São Paulo? O próprio Antonio Candido nos dá o testemunho sobre como a sua geração "teve a sorte de observar de perto os artistas e os escritores famosos que admirava, [...] numa cidade que acabava de completar

49 ANDRADE, Mário, op. cit., I942, p. 24I. Para Mário, “o Rio era muito mais internacional, como norma de vida exterior. Está claro: porto de mar e capital do país, o Rio possui um internacionalismo ingênito. São Paulo era muito mais moderna, porém, fruto necessário da economia do café e do industrialismo consequente. Caipira de serra-acima, conservando até agora um espírito provinciano servil, bem denunciado por sua política, São Paulo estava ao mesmo tempo, pela sua atualidade comercial e pela sua industrialização, em contato mais espiritual e mais técnico com a atualidade do mundo" (grifos nossos).

50 CANDIDO, Antonio, op. cit., 2000, p. I65.

5 I Idem, Iniciação à literatura brasileira, op. cit., p. 88.

52 O modernismo assimilaria a vanguarda europeia com uma inversão de sinais que transformava nossas deficiências em superioridades. 
um milhão de habitantes e em cujo centro concentrado (se for possível falar assim) as pessoas se conheciam de vista"53. Claro está que as pessoas que se "conheciam de vista” eram justamente esses intelectuais, alunos e professores da Faculdade de Filosofia ainda sediada no edifício Caetano de Campos na Praça da República (transferida para a Rua Maria Antonia em I949) e que circulavam pela escola, nas poucas livrarias, nas pouquíssimas galerias, nos bares, cafés e confeitarias ali concentrados, por onde também passavam os artistas e intelectuais que eram por eles admirados, fazendo da rua Barão de Itapetininga o epicentro da sociabilidade universitária. Do Teatro Municipal à Escola Normal, passando pela Confeitaria Vienense e pela Livraria Jaraguá (esta na Rua Marconi), a intelligentsia paulista via e era vista por ali54. Além disso, os dois museus de arte, Museu de Arte de São Paulo - Masp e Museu de Arte Moderna - MAM, ambos fundados em I948 e sediados no edifício dos Diários Associados na Rua Sete de Abril, logo inseriram as artes visuais nesse circuito cultural, passando a disputar o reduzido público intelectualizado com mostras de arte, de cinema, cursos livres e palestras. Tudo isso no centro novo da metrópole - como preconizara Prestes Maia -, a região da Praça da República, onde também a maioria dos cinemas se instalou, fazendo da Ipiranga e da São João a Cinelândia paulista. Antonio Candido notava como naqueles anos "o que se chama de Modernismo, nas artes e na literatura, só então estava ficando pão cotidiano” ao lembrar que o movimento os interessava "sobretudo como atitude mental”, menos até que como linguagem renovadora 55 . À parte o provincianismo que se percebe numa São Paulo que se metropolizava ao mesmo tempo que ainda se contava nos dedos o número de intelectuais que podiam assim ser chamados, a cidade parecia realmente caminhar para uma modernização, ao menos no campo cultural, tendo início aí o seu papel de metrópole cultural que se completa na década seguinte, muito em função das consequências da transferência da capital do país para Brasília em I96056.

Morse coincide com esse juízo e expõe uma ideia geral sobre o significado do modernismo brasileiro se aprofundando no artigo “Brazilian Modernism”, publicado

53 CANDIDO, Antonio. “Clima”. In: . Teresina etc. São Paulo: Ouro sobre Azul, 2007, p. I46.

54 Cf. PRADO, Décio de Almeida. O Clima de uma época. In: AGUIAR, Flavio (Org.). Antonio Candido: pensamento e militância. São Paulo: Humanitas, I999, p. 25-43; e MESQUITA, Alfredo. No tempo da Jaraguá. In: Esboço de figura: homenagem a Antonio Candido. São Paulo: Duas Cidades, I979, p. 39-6I.

55 Mas aqui se trata dos anos de faculdade, dez anos antes da vinda de Morse. Nesse período ele elabora sua crítica do Modernismo, que traz esse movimento para o centro da literatura nacional, a década de I920 como ponto alto dessa manifestação. Cf. CANDIDO, Antonio, op. cit., 2007.

56 Lembremos aqui a formulação do conceito de metrópole como capital cultural: "cidades que se apropriam de certas funções e se tornam centros de intercâmbio cultural, locais onde se preserva a tradição num determinado campo, onde se congregam as novidades mais significativas, onde se concentram os especialistas, onde as inovações são mais prováveis". Seriam ainda “focos de atividade intelectual numa época em que a intelligentsia se ampliava, adquirindo mais autoconsciência enquanto casta, sentindo uma separação crescente em relação às ordens sociais dominantes e se orientando cada vez mais para o futuro e a crença na transformação”. BRADBURY, Malcon. As cidades do Modernismo. In: BRADBURY, Malcon \& MCFARLANE, James (Org.). Guia geral do Modernismo. Tradução de Denise Bottman. São Paulo: Companhia das Letras, I989, p. 77. 
em I950 na Hudson Rewiew, uma das primeiras apreciações sobre o movimento publicada num periódico fora do país ${ }^{57}$. Nesse texto, Morse expõe sua apreciação sobre Mário de Andrade, que teria sido o próprio "modernismo sintetizado, tanto seus valores como em grau menor algumas das suas deficiências" ${ }^{8}$, pois

[...] alguns de seus versos muitas vezes estavam entre os melhores do movimento. Seus contos e sua rapsódia Macunaíma abriram novos temas, uma nova linguagem brasileira para a ficção. [...] Ele foi capaz de criticar mas também indicou um caminho. Esse o seu valor para os mais criativos da nova geração que o seguiram: Drummond de Andrade, Portinari, o compositor Camargo Guarnieri [...], os romancistas do norte, os arquitetos, os historiadores e cientistas sociais 59 .

Mas o mais importante, completava Morse, é que Mário soube que, para acreditar no Brasil, havia que se compreender suas tradições - pois só assim o artista teria um contexto de onde partir e onde se ancorar. De novo, tratava-se de constituir um ethos moderno, sem desprezar a tradição. O que a capital paulista no final da década de I940, para Morse, ainda poderia fazer: modernizar-se sem perder sua tradição ibérica e católica.

\section{ESBOÇO DE LEITURA}

A partir da leitura de Leopoldo Waizbort sobre a obra do crítico brasileiro, retomo aqui a sugestão de prestar atenção ao subtítulo da obra-mestra de Candido, "momentos decisivos", para voltar a Morse e insistir que talvez o norte-americano tenha buscado, menos que recontar a história da cidade de São Paulo, notar os momentos decisivos que mostravam a cidade transformando-se em metrópole. Romantismo e Modernismo são então encarados como índices cruciais não apenas da literatura, mas dos momentos em que a cultura da cidade - usando aqui o termo de Lewis Mumford caro a Morse - manifestou-se de maneira a revelar a "personalidade" da cidade, condensada nas manifestações literárias. Seguindo Waizbort, mesmo havendo "uma sintese operante na Formação [...], não se pretende ali a completude". Teria sido por meio do trabalho com "um conjunto de momentos" que se configurou o todo, pois os

57 MORSE, Richard. Brazilian Modernism. The Hudson Review, v. 3, n. 3, Autumn, I950, p. 447-452. Salvo engano, apenas Roger Bastide já havia falado do Modernismo brasileiro para os estrangeiros (se descontarmos as palestras de Oswald de Andrade na Sorbonne na década de I920): o sociólogo francês, que desde sua chegada a São Paulo exercia uma crítica assídua nos jornais locais, analisando tanto a literatura como a arte modernista, em I943 publica um artigo sobre Mário de Andrade no Bulletin des Études Portuguaises. Cf. PEIXOTO, Fernanda. Diálogos brasileiros: uma análise da obra de Roger Bastide. São Paulo: Edusp, 2000, p. 8I-2. Mas o modernismo brasileiro seria divulgado por Morse numa revista que, fundada em 1947 em Nova York, rapidamente adquiria proeminência na cena intelectual norte-americana, o que permite supor que Morse deve ter ganho com isso alguns pontos na conta dos amigos paulistas.

58 MORSE, op. cit., I950, p. I49

59 Ibidem. 
momentos são decisivos ${ }^{60}$. Configurar um todo sem a pretensão da completude parece ter sido também a intenção da história urbana apresentada por Morse, na qual as distintas esferas da vida social se sobrepõem para dar ao leitor uma compreensão totalizante, sem entretanto encerrar-se em objeto fechado. No movimento de mão dupla que o historiador norte-americano faz ao longo de todo o livro, entre cidade e literatura, ou cidade e cultura, seu interesse está em ver como uma podia alimentar a compreensão da outra, ora se valendo da literatura para ver a cidade, ora fazendo juízo sobre a literatura produzida a partir do que via na cidade. Por isso, para Morse, Mário de Andrade e sua arte encarnaram o espírito moderno de São Paulo, seu ethos, a vida contemporânea afinal, aquela que o próprio historiador vive brevemente em fins dos anos I940 durante suas pesquisas na capital:

Para o artista modernista, assim como para o romântico de há um século, São Paulo proporciona uma experiência de vida que é rica, incisiva e sui generis. Entretanto, a cidade não é um "encravamento" cheio de colorido nativista. Seu espírito, seus traços mais importantes, seu genius loci têm que ser procurados; não são manifestos e avassalantes, como no Rio ou em Salvador. O que é manifesto em São Paulo - movimento, pressa, luzes, trânsito, arranha-céus, fábricas, dinheiro - é universal, sem voz ou contorno explícito. A individualidade íntima da cidade deve ser buscada com sensibilidade e paciência ${ }^{6 r}$.

Se em 1954 Morse optara por um título e subtítulo que rapidamente identificamos como uma história da cidade - De comunidade a metrópole: biografia de São Paulo -, de par com uma história urbana que era feita nos Estados Unidos desde a década de I930 e que em algum sentido ele pôde tomar como mote ${ }^{62}$, a obra evidentemente, como pretendemos ter demonstrado aqui, é muito devedora dos diálogos estabelecidos no Brasil, algo que nos anos seguintes pôde se consolidar em outros termos, mais institucionais, na medida em que o autor também se inseria na academia norte-americana e passava de doutorando em Colúmbia para docente numa das mais importantes universidades daquele país. É desse lugar, como professor de História da América Latina em Yale, que Morse recupera suas relações com os intelectuais brasileiros, convidando-os a participarem de atividades acadêmicas, como palestras, cursos ou congressos, nos Estados Unidos. Entre eles, Sergio Buarque, Celso Furtado, Antonio Candido, Florestan Fernandes, por este ou aquele motivo, estiveram em Yale

60 WAIZBORT, Leopoldo. A passagem dos três ao um: crítica literária, sociologia, filologia. São Paulo: Cosac Naify, 2007, p. 9I.

6I MORSE, Richard, op. cit., I954, p. 283.

62 Não caberia aqui desenvolver o ponto, remeto apenas ao livro organizado por Bruce Stave, que, por meio de entrevistas com os fundadores da história urbana norte-americana, apresenta um panorama das questões que animaram e animam o debate. Cf. STAVE, Bruce (Ed.). The making of urban history: historiography through oral history. Beverly Hills: Sage Publications, I977. 
a convite de Morse em breves visitas ou longas temporadas ${ }^{63}$. Dessa forma, quando, em I970, o livro foi reeditado com o título com o qual se tornou de fato conhecido, Formação histórica de São Paulo: de comunidade a metrópole, parte da Coleção Corpo e Alma do Brasil, dirigida por Fernando Henrique Cardoso, a mudança também indica sua identificação com aqueles intelectuais brasileiros comprometidos com a ideia da formação $0^{64}$. Morse, que se identificava (eventualmente mais que os próprios paulistas) com o Modernismo - sendo ele mesmo esse "espírito modernista" por assim dizer -, buscava achar o lugar daquela metrópole da periferia do capitalismo, querendo ver nessa excentricidade uma vantagem. Ao ter o título alterado para Formação, reconhece-se no trabalho de Morse mais um desses esquemas de interpretação que pudesse "sustentar a evolução", no caso da sociedade paulista, em seu sentido "normativo e descritivo", entretanto, sem correr na "direção do ideal europeu de civilização" 65 , buscando um ideal de civilização próprio, no sentido em que os artistas modernistas pensavam ${ }^{66}$. A ideia de formação, que estava implícita no livro de Morse desde sempre - mesmo que na edição de I954 pudesse não estar claro para o próprio autor -, mostrava como ele dera conta de apresentar o desenvolvimento da cidade que vinha se configurando "ao longo de um processo cumulativo de articulação com a sociedade e adensamento artístico"67 (aqui diríamos, cultural), compartilhando dessa tradição que soube dar uma "forma metódica ao conteúdo básico da experiência intelectual brasileira"68, dando uma forma metódica nesse caso à própria experiência urbana paulista. Não se trata aqui de dizer que Morse "antecipa" o esquema de Candido obviamente, mas de propor que, ao conviver com a formulação do mesmo, tenha se deixado "contaminar" por algumas daquelas ideias, que acabaram por

63 GUIDE to the Richard McGee Morse Papers Manuscripts \& Archives Library, Series III, Box 7. Compiled by Matthew T. MacLean. New Heaven: Yale University, November I998. Antonio Candido relatou haver dois momentos de amizade com Morse, um primeiro na sua vinda a São Paulo, em que os dois jovens se conhecem e estabelecem uma breve relação com base numa afinidade imediata, e um segundo, ambos professores respeitados em seus campos de conhecimento, quando Morse o convida para uma temporada em Yale como professor visitante, a qual ele recusa - não sem uma breve passada pela universidade. Cf. depoimento de Antonio Candido à autora, I6/3/20Io, apud CASTRO, Ana. Um americano na metrópole (latino-americana)..., op. cit., 20I3, p. 2 I5.

64 Paulo Arantes explorou "o sentido da formação" na experiência intelectual brasileira, descrevendo como ela em muitas oportunidades se deu "na forma de grandes esquemas interpretativos em que se registram tendências reais na sociedade, tendências às voltas, não obstante, com uma espécie de atrofia congênita que teima em abortá-las, [deste modo] apanhava-se naquele corpus de ensaios sobretudo o propósito coletivo de dotar o meio gelatinoso de uma ossatura moderna que lhe sustentasse a evolução”. ARANTES, Paulo, op. cit., I997, p. II-66. p. I2.

65 Ibidem, p. 20.

66 Macunaíma foi no fundo esse ideal - sem nenhum espaço para romantismos (no sentido vulgar da palavra) -, ao mostrar o "nenhum caráter" que o fazia "herói de nossa gente”. Cf. ANDRADE, Mário de. Macunaíma: o herói sem nenhum caráter [I928]. Belo Horizonte: Itatiaia, I985.

67 ARANTES, Paulo, op. cit., p. 2 I.

68 Ibidem. 
alimentar a sua reflexão. Morse, ao falar da vida na cidade - compreendendo, como ele diz a certa altura, o "temperamento" da metrópole -, parece fazer coro aos modernistas, mas também a seus herdeiros.

O historiador norte-americano, nesse sentido, também ajudou a definir a "identidade" moderna de São Paulo com sua obra, identidade que havia sido forjada pelos próprios modernistas em suas crônicas, contos, romances e poesias e que naquele momento começava a ser vista sob os olhos do pensamento universitário por meio do trabalho crítico. Por isso talvez a longevidade e o interesse de sua obra ainda hoje.

\section{SOBRE A AUTORA}

ANA CLAUDIA VEIGA DE CASTRO é professora do Departamento de História da Arquitetura e Estética do Projeto da Faculdade de Arquitetura e Urbanismo da Universidade de São Paulo (FAU/USP).

E-mail: anacvcastro@gmail.com

\section{REFERÊNCIAS BIBLIOGRÁFICAS}

ANDRADE, Mário de. Macunaíma: o herói sem nenhum caráter [I928]. Belo Horizonte: Itatiaia, I985. . O movimento modernista. In: Aspectos da literatura brasileira. São Paulo: Martins, I942, p. 24I-50.

ARANTES, Paulo. Providências de um crítico literário na periferia do capitalismo. In: ARANTES, Paulo; ARANTES, Otilia Beatriz Fiori. Sentido da formação: três estudos sobre Antonio Candido, Gilda de Mello e Souza e Lucio Costa. São Paulo: Paz e Terra, I997, p. II-66.

BOMENY, Helena. Uma entrevista com Richard Morse. Estudos históricos, Rio de Janeiro: FGV, v. 2, n. 3, I989, p. 77-93.

BRADBURY, Malcon. “As cidades do modernismo”. In: BRADBURY, Malcon \& MCFARLANE, James (Org.).

Guia geral do Modernismo. Tradução Denise Bottman. São Paulo: Companhia das Letras, I989, p. 73-82. BRUNO, Ernani da Silva. História e tradições da cidade de São Paulo, São Paulo: Jose Olympio, I954. 3 v.

CANDIDO, Antonio. Formação da literatura brasileira: momentos decisivos. São Paulo: Martins, I959. 2 v. . Young Mr. Morse. In: BOMENY, Helena (Org.). Um americano intranquilo. Rio de Janeiro: Ed. FGV, I992, p. 7-I2.

. A literatura na evolução de uma comunidade (I954). In: . Literatura e sociedade: estudos de teoria e história literária. São Paulo: T. A. Queiroz, 2000, p. I39-68.

. Iniciação à literatura brasileira. Rio de Janeiro: Ouro sobre Azul, 2004. . O Romantismo no Brasil. São Paulo: Humanitas, 2004. .Clima”. In: . Teresina etc. São Paulo: Ouro sobre Azul, 2007, p. I4I-I56.

CARDOSO, Fernando Henrique. A fome e a crença (sobre Os Parceiros do Rio Bonito). In: Esboço de figura: homenagem a Antonio Candido. São Paulo: Duas Cidades, I979, p. 89-Ioo . 
CARVALHO, Maria Alice Rezende de. Morse e o mar. In: . Quatro vezes cidade. Rio de Janeiro: 7 Letras, I994, p. I05-I22.

CASTRO, Ana. Um americano na metrópole (latino-americana): Richard Morse e a história cultural urbana de São Paulo, I947-I970. Tese (Doutorado - Área de Concentração: História e Fundamentos da Arquitetura e Urbanismo). Faculdade de Arquitetura e Urbanismo - FAU, Universidade de São Paulo - USP, 20I3. . Leituras e leitores de Richard Morse: a trajetória de um livro sobre a formação da metrópole paulista. Anais do Museu Paulista, São Paulo, v. 2I, 20I3, p. I79-I93.

DANTAS, Vinicius. Apresentação. In: Antonio Candido. Textos de intervenção. Seleção, apresentação e notas de Vinicius Dantas. São Paulo: Duas Cidades e Ed. 34, 2009, p. I5-36.

GUIDE to the Richard McGee Morse Papers Manuscripts \& Archives Library, Series III, Box 7. Compiled by Matthew T. MacLean. New Heaven: Yale University, November 1998.

JACKSON, Luiz Carlos. A tradição esquecida. Os Parceiros do Rio Bonito e a sociologia de Antonio Candido. Belo Horizonte: UFMG; São Paulo: Fapesp, 2002.

MESQUITA, Alfredo. No tempo da Jaraguá. In: Esboço de figura: homenagem a Antonio Candido. São Paulo: Duas Cidades, I979, p. 39-6I.

MONBEIG, Pierre. La croissance de la Ville de São Paulo. Grenoble: Institut et Revue de de Géographie Alpine, I953.

MORSE, Richard. O pesquisador social e o historiador moderno. Revista do Arquivo Municipal, São Paulo, n. II3, I949, p. 36-52. . Brazilian Modernism. The Hudson Review, v. 3, n. 3, Autumn, p. 447-452, I950. . São Paulo. City under the empire (I822-I889). Tese (Doutorado). New York: Columbia University, I952. . De comunidade a metrópole: biografia de São Paulo. São Paulo: Fundação do IV Centenário, I954. . From Community to Metropolis: a biography of São Paulo, Brazil. Gainsville: Florida University Press, I958.

. Formação histórica de São Paulo: de comunidade a metrópole. São Paulo: Difel, I970.

MOTA, Carlos Guilherme. Um americano intranquilo. In: BOMENY, Helena (Org.). Um americano intranquilo. Rio de Janeiro: Ed. FGV, I992, p. I3-20.

PEIXOTO, Fernanda, Diálogos brasileiros: uma análise da obra de Roger Bastide. São Paulo: Edusp, 2000.

PESAVENTO, Sandra. Muito além do espaço: por uma história cultural do urbano. Estudos históricos, Rio de Janeiro: FGV, n. I6, I995, p. 279-90.

PONTES, Heloisa. Destinos mistos: os críticos do Grupo Clima em São Paulo (I940-68). São Paulo: Companhia das Letras, 1998.

PRADO, Décio de Almeida. O Clima de uma época. In: AGUIAR, Flavio (Org.). Antonio Candido: pensamento e militância. São Paulo: Humanitas, I999, p. 25-43.

RAMASSOTE, Rodrigo Martins. Antonio Candido em Assis e depois. Revista do Instituto de Estudos Brasileiros, USP, São Paulo, n. 50, mar. 2010, p. I03-28.

STAVE, Bruce (Ed.). The making of urban history: historiography through oral history. Beverly Hills: Sage Publications, I977.

SÜSSEKIND, Flora. Rodapés, tratados e ensaios: a formação da crítica brasileira moderna. In:

Papéis colados. Rio de Janeiro: Ed. UFRJ, 2002, p. I5-36.

WAIZBORT, Leopoldo. A passagem dos três ao um: crítica literária, sociologia, filologia. São Paulo: Cosac Naify, 2007. 